\title{
Chronic Daily Headache in Children and Adolescents
}

\author{
Shashi S. Seshia
}

\begin{abstract}
Objective: Characterize chronic daily headache in those less than 20 years of age. Material and methods: Study design: Prospective, observational, and sequential. Setting: Private practice Pediatric Neurology Clinic in a Canadian city (Winnipeg). Patients and data collection: Data on those referred with headache between September 1998 and December 2001 were entered on data sheets. Patients were followed up for one month to four years. Results: One hundred and forty-three (31\%) of 463 referred with headache had chronic daily headache with duration of one month to five years (median: eight months). The age range was 5.5 years to 20 years (median: 13 years). There were significantly more females $(\mathrm{N}=93)$ than males $(\mathrm{N}=50)$. The main groups were: $(1)$ transformed migraine: $6(4 \%)$, (2) transformed tension-type headache: $80(56 \%)$ and (3) transformed comorbid migraine and tension-type headache: 39 (27\%). Tension-type features dominated in 94\%. Analgesia overuse occurred in two. Stressors were recognized in 60 (42\%); anxiety disorder was diagnosed in $8(6 \%)$, and depression in $13(9 \%)$. Computed tomography scans were done in 31 (22\%), and MRI/MR angiography in $8(6 \%)$ and were normal or showed nonspecific incidental findings. Twenty-two (15\%) were lost to follow-up; 115 of the remaining 121 (95\%) were headache free or greatly improved, 63 (55\%) without specific treatment. Conclusions: Chronic daily headache is a common headache disorder in children and adolescents, especially in teenage girls. A prospective neuropsychiatric approach is necessary for evidenced-based management, since the condition has mental health, social and economic ramifications.
\end{abstract}

RÉSUMÉ: Céphalée quotidienne chronique chez les enfants et les adolescents. Objectif: Le but de cette étude était de caractériser la céphalée quotidienne chronique chez les moins de 20 ans. Matériel et Méthodes: Il s'agit d'une étude d'observation prospective et séquentielle en clinique privée de neurologie pédiatrique à Winnipeg, au Canada. Les données ont été recueillies chez des patients référés pour céphalée de septembre 1998 à décembre 2001. La durée du suivi était de 1mois à 4 ans. Résultats: Cent quarante-trois (31\%) des 463 patients référés pour céphalée présentaient une céphalée quotidienne chronique qui durait depuis un mois à cinq ans (médiane: 8 mois). Les patients avaient entre 5 ans et demi et 20 ans (médiane: 13 ans). Il y avait beaucoup plus de filles $(\mathrm{N}=93)$ que de garçons $(\mathrm{N}=50)$. Ils ont été répartis en trois groupes: migraine transformée, $6(4 \%)$; céphalée de tension transformée (CTT), 80 (56\%); et migraine comorbide transformée et CTT, 39 (27\%). Les caractéristiques la céphalée de tension dominaient chez $94 \%$ et l'abus de médicaments analgésiques était présent chez 2 . Des facteurs de stress ont été identifiés chez 60 (42\%); un trouble anxieux a été diagnostiqué chez 8 (6\%) et une dépression chez 13 (9\%). Trente et un patients $(22 \%)$ ont subi une tomodensitométrie et $8(6 \%)$ ont subi une angiographie par résonance magnétique qui se sont avérées normales ou qui montraient des anomalies non spécifiques dont la découverte était fortuite. Vingtdeux patients (15\%) ne se sont pas présentés pour un suivi; 115 des 121 patients restants (95\%) ne présentaient plus de céphalée ou étaient très améliorés lors du suivi, dont 63 (55\%) sans traitement spécifique. Conclusions: La céphalée quotidienne chronique est un type de céphalée qui est fréquent chez les enfants et les adolescents, surtout parmi les filles. Il faut avoir recours à une approche neuropsychiatrique tel que recommandé pour la prise en charge basée sur les données actuelles de la science parce que cette pathologie a des ramifications sociales, économiques et de santé mentale.

Can. J. Neurol. Sci. 2004; 31:319-323

Mathew et al $^{1}$ first characterized chronic daily headache $(\mathrm{CDH})$ in adults. The International Headache Society (IHS) Classification, ${ }^{2,3}$ does not incorporate $\mathrm{CDH}$ as a separate entity. Silberstein et $\mathrm{al}^{4}$ proposed a classification for $\mathrm{CDH}$; they recognized that further modifications to their proposal would occur. Gladstein et $\mathrm{al}^{5}$ highlighted the need to study $\mathrm{CDH}$ in

\footnotetext{
Presented at the 38th Meeting of the Canadian Congress of Neurological Sciences, June 17-21, 2003, Quebec City, Canada

From the Manitoba Clinic, Winnipeg, MB, Canada.

ReCEIVED MAY 26, 2003. ACCEPTED INFINALForm November 27, 2003.

Reprint requests to: S.S. Seshia, Division of Pediatric Neurology, Royal University Hospital, 103, Hospital Drive, Saskatoon, SK. 7N 0W8 Canada.
} 
children and adolescents (hereafter referred to collectively as children) separately from adults. This study reports on 143 children with this disorder.

\section{Materialand Methods}

\section{Patients and setting}

The data on children referred primarily with headache to the Pediatric Neurology Clinic at the Manitoba Clinic, Winnipeg, were entered on standardized data sheets. Children and guardians were interviewed together and children were then interviewed separately. They were asked to estimate the relative frequency of individual features. The information about headache was, therefore, a composite from child and guardian. After the first assessment and discussion, all were offered follow-up appointments and instructed to fill in a headache calendar prospectively for further review. They were advised to describe each headache type and code them (example Type A, Type B etc); frequency was recorded for individual days and separately for day and night, duration was recorded numerically or by shading the area in a day calendar and severity was graded on a numerical pain scale. Those discharged from further follow-up because $\mathrm{CDH}$ had resolved were encouraged to contact the author if headaches recurred. Families were telephoned if they failed to keep appointments.

\section{Study period and design}

Data were collected prospectively and sequentially from September 1998 to December 2001. Those in whom headache was not the presenting complaint (but in whom a history of headache may have been obtained "on inquiry") were excluded.

\section{Definitions and classification}

Recurrent headache was defined as the occurrence of headache for $<15$ days a month, irrespective of attack duration. Chronic daily headache was defined as the occurrence of headache for at least four hours a day, at least 15 days per month for a month or more. ${ }^{4}$ Headaches were classified according to the IHS Classification, ${ }^{2}$ the criteria for migraine without aura being

\section{Table 1: Criteria for migraine without aura ${ }^{6,7}$}

A. At least five attacks fulfilling B-D

B. Headache attacks lasting 30 minutes to 48 hours

C. Headache with at least two of the following characteristics:

1. Unilateral or bilateral location

2. Pulsating quality

3. Moderate or severe intensity (inhibits or prohibits daily activities)

4. Aggravation by routine physical activity

D. During headache, at least one of the following symptoms:

1. Nausea and/or vomiting

2. Photophobia and/or phonophobia

E. As in original International Headache Society Document
Table 2: Types of chronic daily headache $(\mathrm{N}=143)$

\section{Type}

Transformed migraine

Transformed TTH

Transformed comorbid migraine and TTH

New onset

Post-traumatic with TT features

Not classifiable

$\begin{array}{rr}\text { No. } & \% \\ 6 & 4 \\ 80 & 56 \\ 39 & 27 \\ 2 & 1.5 \\ 14 & 10 \\ 2 & 1.5\end{array}$

TTH=tension-type headache

modified for children (Table 1). ${ }^{6,7}$ Chronic daily headache was classified according to the proposal of Silberstein et al, ${ }^{4}$ with the exception of headache with features of both migraine and tension-type (TT), which was classified as comorbid migraine and TT. ${ }^{5}$ Analgesia overuse was arbitrarily defined as the use of analgesics at least once daily, five days or more a week, for more than two weeks.

\section{Statistical analyses}

Fisher's Exact Test was used to determine significance between groups, with level set by convention at 0.05 .

\section{RESUltS}

\section{General data}

Four hundred and sixty-three children were referred for headache during the study period. Three hundred and twenty $(69 \%)$ had recurrent headache and $143(31 \%)$ had $\mathrm{CDH}$. The ages of the 143 with $\mathrm{CDH}$ ranged from $5 \frac{1}{2}$ years to 20 years (the upper limit of adolescence), with a median age of 13 years. Headache duration ranged from one month to four years with a median of eight months. A family history of headache in first or second-degree relatives (parents, siblings, grandparents, uncles, or aunts) was obtained in $85 \%$.

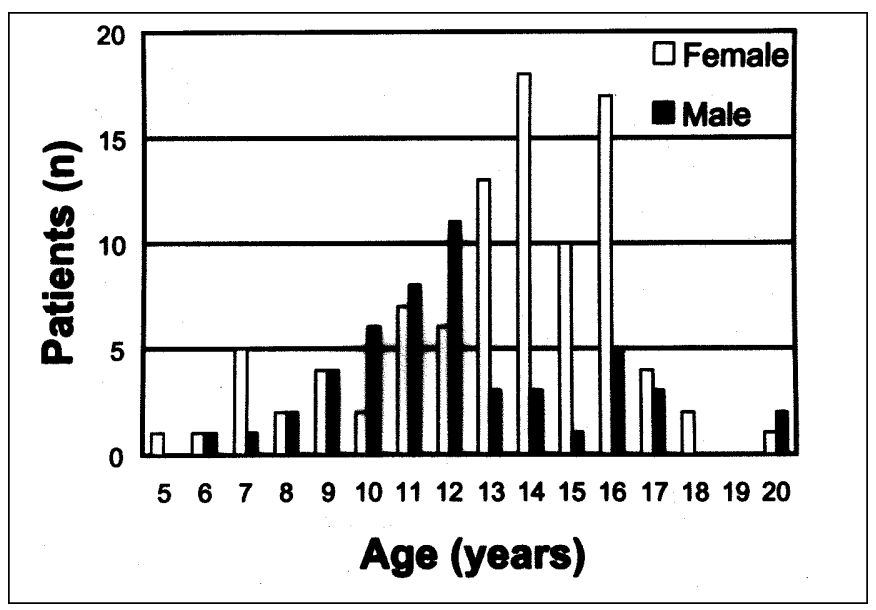

Figure: Age and gender distribution of children with $\mathrm{CDH}$ 


\section{Gender and age (Figure)}

There were significantly $(\mathrm{p}<.001)$ more females $(\mathrm{N}=93$ or $65 \%$ ) than males $(\mathrm{N}=50$ or $35 \%)$ in patients with $\mathrm{CDH}$, particularly when compared to the 320 with recurrent headache seen over the same period (females: 148 or $46 \%$; males: 172 or $54 \%$ ). The median and modal ages for females with $\mathrm{CDH}$ were both 14 years and for males 12 years, respectively.

\section{Types of CDH (Table 2)}

The majority $(\mathrm{N}=125 ; 87 \%)$ gave a history of recurrent headache that had gradually transformed over weeks or months to become $\mathrm{CDH} ; 4 \%$ had transformed migraine; $27 \%$ developed $\mathrm{CDH}$ on a background of comorbid TTand migraine whilst $56 \%$ developed $\mathrm{CDH}$ on a background of tension-type headache (TTH) alone (episodic TTH transforming into chronic TTH). Thus, of the 143 children in the study, 94\% had TT characteristics. Analgesia overuse occurred in two patients; both had comorbid TTH and migraine.

\section{Other features}

Stressors that child, family and the author jointly felt were likely important factors in causing $\mathrm{CDH}$ were identified in 60 $(42 \%)$. Anxiety disorder was diagnosed in nine $(6 \%)$ and depression in $13(9 \%)$. Stressors could be classified as those related to school (such as poor performance, bullying), peers, parental separation, or family (for example: relationship issues, serious illness in a family member, control over decisions, geographic relocation etc.).

Nausea, photophonobia, photophobia, and aggravation by physical activity occurred variably at different times in all patients; none experienced vomiting. Despite constant daytime headache, none was awakened from night time sleep. Headache severity varied through the day. None had exclusively localized headache. Headaches were generalized, often maximal in the frontal and temporal regions. Headaches were described as the equivalent of constant or pressure-like with intermittent throbbing or sharp pains superimposed.

The data sheet included school absences from headache, times parents missed work or had their routine interrupted to pick their child up from school because of headache, as variables. Precise information in this regard was not available on any child.

Five children who were unable to attend school and participate in extracurricular activities for two weeks or more, were considered to have severe disabling $\mathrm{CDH}$. For the most part, the remaining 138 continued with their routine and were considered to have mild or moderate $\mathrm{CDH}$.

All subjects had normal neurological and general physical examinations that included recording blood pressure, sinus tenderness, assessing visual acuity and checking for trigger points.

\section{Neuroradiology}

Computed tomography (CT) scans were done in $31(21 \%)$ and magnetic resonance imaging (MRI) scans with or without MR angiography in eight (6\%) and were normal or showed nonspecific incidental findings. Almost all CT scans had been ordered by referring physicians.

\section{Follow-up}

Twenty-two of the 143 patients (15\%) were lost to follow-up
Table 3: Treatment and Outcome $(\mathrm{N}=143)$

\begin{tabular}{lcc}
\hline Treatment & No.(\%) & resolved \\
Amitryptiline & $31(22)$ & 28 \\
Gabapentin & $5(3.5)$ & 5 \\
Psychiatric consultation & $29(20)$ & 25 \\
Other (eg. paxil) & $3(2)$ & 3 \\
IV DHE+metoclorpramide & $5(3.5)$ & 5 \\
No specific treatment & $63(55)$ & 63 \\
No follow-up & $22(15)$ &
\end{tabular}

Note: some children received more than one treatment

IV DHE= Intravenous dihydroergotamine

despite telephone reminders; seven of the 22 had normal CT/MRI scans. The remaining 121 children were followed up for periods of one month to four years (median: six months), typically until headaches were not considered to be a problem for child and family.

Only 24 of the 121 who kept follow-up appointments brought their headache charts back and none provided any detailed written description of headache type or severity. Hence, the diagnosis of headache type/s at the follow-up visit was, as at the first assessment, based on verbal information. In none did the clinical impression change between assessments.

\section{Treatment and outcome (Table 3)}

Of the 121 in whom follow-up information was available, headaches resolved or were greatly improved in 115 (95\%), in 63 $(55 \%)$ without drug intervention. The treatment approaches in the remaining 58 are summarized in Table 3. Treatment with amitryptiline or gabapentin was continued for a three-month headache free period before gradual withdrawal.

Five children were admitted for a course of IV dihydroergotamine and metoclorpramide ${ }^{8}$ with complete resolution of the headache. Three of these five have had one or two relapses, one of them requiring readmission for another course. Another child who remitted with oral amitryptiline relapsed after withdrawal but responded to reintroduction of amitryptiline.

\section{DiscuSSION}

Thirty-one percent of children with headache referred to the author during the study period had $\mathrm{CDH}$, almost identical to the frequency reported by Abu-Arafeh, ${ }^{9}$ Canestri et $\mathrm{al}^{10}$ and Hershey et al. ${ }^{11}$ There are several clinical similarities between the author's experience in Winnipeg, Canada and that of AbuArafeh $^{9}$ from Glasgow, Scotland. Viswanathan et al ${ }^{12}$ found $15 \%$ of their patients had CDH. Koenig et al ${ }^{13}$ discussed 189 patients with $\mathrm{CDH}$, enrolled prospectively through nine tertiary headache clinics in the United States over an unspecified two years. They do not refer to the sample size of all those with headache during the same period. Chronic daily headache is reported in about $30 \%$ to $90 \%$ of adults with headache referred to specialized headache clinics. ${ }^{14}$

Chronic daily headache occurred more often in girls $(65 \%)$ 
than in boys (35\%), comparable to the experience of Canestri et $\mathrm{al}^{10}$ (females 67\%), Hershey et al (68\%), ${ }^{11}$ Koenig et al ${ }^{13}$ (females 70\%), and Gladstein and Holden (females 78\%). ${ }^{15}$ The median and modal ages (14 years) of girls with $\mathrm{CDH}$ were slightly higher than those (12 years) of the boys. The current study was not designed to define the reasons for gender differences.

Silberstein et $\mathrm{al}^{4}$ arbitrarily opined that patients could not be diagnosed with chronic TTH if they also met the criteria for transformed migraine, an approach that would misclassify those with mixed migraine and tension-type $\mathrm{CDH}$ as transformed migraine. Gladstein and Holden ${ }^{15}$ suggested a "comorbid" category to describe children with features of TT and migraine. Gladstein et $\mathrm{al}^{5}$ and Koenig et $\mathrm{al}^{13}$ emphasized the close association between migraine and tension-type features in children with $\mathrm{CDH}$ and endorsed "the concept of a headache continuum, rather than distinct migraine and tension-type headache syndromes, in children and adolescents with CDH". Twenty-seven percent of children with $\mathrm{CDH}$ in the current study, $30.4 \%$ of those reported by Abu-Arafeh ${ }^{9}$ and $40 \%$ of those in the study of Gladstein and Holden ${ }^{15}$ experienced features of both migraine and TTH through the duration of $\mathrm{CDH}$, lending further strength to the concept for a continuum between the two headache types, at least in children. The co-occurrence of chronic migraine and chronic TTH is now acknowledged by the IHS. ${ }^{3}$ We have previously suggested that the failure to recognize such an association could force clinicians to classify subjects into one or other category and create a potential for inappropriate management. ${ }^{16}$

Tension-type characteristics dominated the headache features in $94 \%$ of the patients in the current study, a percentage similar to that reported by Abu-Arafeh. ${ }^{9}$

Two children (1.4\%) "over-used" analgesics but in neither did headache resolve when analgesics were discontinued; hence, they cannot be classified as $\mathrm{CDH}$ due to analgesia overuse. ${ }^{2}$ Vasconcellos et al $^{17}$ discussed analgesic rebound headache in children and adolescents but did not define analgesia over-use. Analgesia overuse is considered an important contributor to CDH in adults. ${ }^{18}$ Silberstein and Welch ${ }^{19}$ have recently discussed medication overuse headache diagnostic criteria. We need physiologically and pharmacologically based criteria for children.

Minor head trauma, typically a Grade I sports related concussion, ${ }^{19}$ was a "secondary" cause of $\mathrm{CDH}$ in 14 children $(10 \%)$. The history of injury was rarely volunteered. Hence, in any child with new onset $\mathrm{CDH}$, a history of head trauma sustained in the course of sports or recreational activity should be sought.

There were no examples of chronic paroxysmal hemicrania type of $\mathrm{CDH}$ in the current study, an entity considered uncommon in children. ${ }^{20}$

Bigal et $\mathrm{al}^{21}$ found an association between the emergence of $\mathrm{CDH}$ sub-types with asthma, hypertension, hypothyroidism, daily consumption of caffeine and consumption of alcohol more than three times a week in adults. The relevance of their findings to children is uncertain.

The current study was not designed to assess the role for neuroradiologic investigations or treatment in an evidencedbased manner. None of the 121 patients who were followed up had an intracranial lesion; as in the study of Abu-Arafeh, ${ }^{9}$ only a minority $(21 \%)$ had CT scans and an even smaller number had MRI scans/MRI angiography (6\%), results being normal or unremarkable in all. The MRI scans were done to clarify incidental lesions found on CT scans. An MRI scan with MR angiography was done in those children who had a family history of aneurysm or in whom headaches worsened considerably with physical activity. Our experience is similar to that of Lewis and Dorbad, ${ }^{22}$ supporting their suggestion (Level III evidence), that routine neuroimaging is not warranted in neurologically normal children with $\mathrm{CDH}$.

Despite the relative constancy of the headache, only five $(3.5 \%)$ of the 143 children had $\mathrm{CDH}$, severe and disabling enough to prohibit routine for two weeks continuously or more. Their clinical features were otherwise similar to those in children with mild or moderate $\mathrm{CDH}$. All nine children with $\mathrm{CDH}$ from an earlier hospital based practice had severe disabling $\mathrm{CDH} .{ }^{23}$

Over half of those in the current study improved without specific therapy. Redillas and Solomon ${ }^{24}$ have discussed the pharmacological approaches to $\mathrm{CDH}$. All five children with severe disabling $\mathrm{CDH}$ treated with a course of IV dihydroergotamine and metoclorpramide ${ }^{8}$ had complete cessation of headache within 48 hours; a placebo effect cannot be excluded. Children and adolescents have higher placebo rates than adults. ${ }^{25}$

PedMidas ${ }^{26}$ could not be used to objectively assess disability caused by $\mathrm{CDH}$ because the required information was vague. Often, children and adolescents are limited historians. ${ }^{13,16}$ Koenig et $\mathrm{al}^{13}$ had similar challenges in obtaining precise descriptions and their analyses were also based on data collected at the first evaluation.

Headaches resolved completely or were not considered a management issue by $95 \%$ of those who were re-evaluated. AbuArafeh $^{9}$ and Canestri et al ${ }^{10}$ also reported favorable outcomes in their respective groups. Follow-up data are not available in the study of Koenig et al. ${ }^{13}$ The long-term natural history of $\mathrm{CDH}$ in children is unknown.

Stressors were considered to play an important role in causing $\mathrm{CDH}$ in $42 \%$. Given the qualitative and subjective nature of the data, the author is reluctant to expand further since there were no controls for comparison. The realities of clinical practice made it impossible to have all children assessed by a child psychiatrist or psychologist. Abu-Arafeh ${ }^{9}$ also emphasized the role of stressful events in causation. Stewart et $\mathrm{al}^{27}$ found an association between "stressful life events" and the occurrence of $\mathrm{CDH}$ in adults. Neither provided details. Anxiety and depression occurred in 6\% and $9 \%$ of children in the current study. Canestri et al ${ }^{10}$ also reported anxiety and mood disorders in their subjects with $\mathrm{CDH}$.

There are no population based studies on children with $\mathrm{CDH}$. The selection and related biases in the current study are similar to those in other clinical studies on children with headache.9,11-13,15-17,23

The just published revised IHS Classification ${ }^{3}$ does not recognize $\mathrm{CDH}$ as a distinct category. Rather, chronic migraine and probable chronic migraine (IHS Codes 1.5.1 and 1.6.5 respectively) are incorporated as migraine sub-types; chronic TTH and probable chronic TTH (IHS Codes 2.3 and 2.4.3 respectively) are sub-types of TTH. 'Chronic' is defined as persistence of headache for more than three months. The new Classification $^{3}$ is not discussed further as my study pre-dated its publication. 
There are no studies directly comparing headaches in children with those in adults. However, the literature ${ }^{5,13,15}$ suggests important differences that classification schemes must recognize, a sentiment expressed by Abu-Arafeh ${ }^{9}$ in 2001 and, more recently, by Bigal et al. ${ }^{28}$ Chronic daily headache is a common headache disorder in children, with psychosocial factors playing an important role in causation. A prospective neuropsychiatric approach is imperative.

\section{ACKNOWLEDGEMENTS}

The author thanks the Manitoba Clinic for help with chart retrieval and the Children's Research Foundation of Manitoba Inc., for financial support. The author thanks Mr. Don Cates for statistical analysis, and Drs.Victor Chernick, Dawn Hartfield, Molly Seshia, Jerry Yager and Samuel Wiebe for helpful suggestions.

\section{Disclosure}

The author has received honoraria from GlaxoSmithKline for speaking at three meetings organized by the company.

\section{REFERENCES}

1. Mathew NT, Stubits E, Nigam MP. Transformation of episodic migraine into daily headache: analysis of factors. Headache 1982; 22: 66-68.

2. Headache Classification Committee of the International Headache Society. Classification and Diagnostic Criteria for Headache Disorders, Cranial Neuralgias and Facial Pain. Cephalalgia 1988; 8(Suppl 7): 1-96.

3. Headache Classification Subcommittee of the International Headache Society. The International Classification of Headache Disorders. 2nd ed. Cephalagia 2004; 24 (Suppl 1): 1-152.

4. Silberstein SD, Lipton RB, Sliwinski M. Classification of daily and near-daily headaches: field trial of revised I.H.S. Criteria. Neurology 1996; 47: 871-875.

5. Gladstein J, Holden W, Winner, P, et al. Chronic daily headache in children and adolescents: current status and recommendations for the future. Headache 1997; 37: 626-629.

6. Seshia SS, Wolstein JR. International Headache Society Classification and Diagnostic Criteria in Children: a proposal for revision. Dev Med Child Neurol 1995; 37:879-882.

7. Winner P, Martinez W, Mate L, Bello L. Classification of pediatric migraine: proposed revisions to the I.H.S. Criteria. Headache 1995; 35: 407-410.

8. Linder SL. Treatment of childhood headache with dihydroergotamine mesylate. Headache 1994; 34: 578-580.
9. Abu-Arafeh I. Chronic tension-type headaches in children and adolescents. Cephalalgia 2001; 21:830-836.

10. Canestri P, Galli F, Uidetti VG, Tomaciello A. Chronic daily headache $(\mathrm{CDH})$ in children and adolescents: a 2 year follow-up study. Cephalalgia 2001; 21: 288.

11. Hershey AD, Powers SW, Bentti A-L, LeCates S, deGrauw TJ. Characterization of chronic daily headaches in children in a multidisciplinary headache center. Neurology 2001; 56:10321037.

12. Viswanathan V, Bridges SJ, Whitehouse W, Newton RW. Childhood headaches: discrete entities or continuum? Dev Med Child Neurol 1998; 40: 544-550.

13. Koenig MA, Gladstein J, McCarter RJ, et al. Chronic daily headache in children and adolescents presenting to tertiary headache clinics. Headache 2002; 42; 491-500.

14. Saper JR. Chronic daily headache. Cephalagia 2001; 21: 252.

15. Gladstein, J, Holden W. Chronic daily headache in children and adolescents: a 2-year prospective study. Headache 1996; 36:349351.

16. Seshia SS, Wolstein JR, Adams C, Booth FA, Reggin JD. International headache society criteria and childhood headache. Dev Med Child Neurol 1994; 36: 419-428.

17. Vasconcellos E, Pina-Garza JE, Millan EJ, Warner JS. Analgesic rebound headache in children and adolescents. J Child Neurol 1998; 13:443-447.

18. Silberstein SD, Welch KMA. Painkiller headache. Neurology 2002; 59:972-974.

19. Cantu RC. Minor head injuries in sports. Adolesc Med 1991; 2:141154.

20. Winner P, Gladstein J. Chronic daily headache in pediatric practice. Curr Opin Neurol 2002; 15: 297-301.

21. Bigal ME, Sheftell FD, Rapoport AM, et al. Chronic daily headache: identification of factors associated with induction and transformation. Headache 2002; 42: 575-581.

22. Lewis DW, Dorbad D. The utility of neuroimaging in the evaluation of children with migraine or chronic daily headache who have normal neurological examinations. Headache 2000; 40: 629-632.

23. Seshia SS, Sigurdson E. Chronic daily headache in children. Can J Neurol Sci 1996; 23: (Suppl 1) S80.

24. Redillas C, Solomon S. Prophylactic pharmacologic treatment of chronic daily headache. Headache 2000; 40: 83-102.

25. Diener HC. Placebo. Cephalagia 2001; 21: 248.

26. Heshey AD, Powers SW, Vockell ALB, et al. PedMidas. Neurology 2001; 57:2034-2039.

27. Stewart WF, Scher AI, Lipton RB. Stressful life events and risk of chronic daily headache: results from the frequent headache epidemiology study (FRHE). Cephalagia 2001; 21: 279.

28. Bigal ME, Lipton RB, Silberstein SD. Re: Chronic daily headache in children and adolescents presenting to tertiary care clinics. Headache 2003; 43: 419-421. 